\title{
El mundo océano. José Joaquín de Mora escribe para el público hispanoamericano (1825- 1830)
}

Rosalía Baltar

CELEHIS -Universidad Nacional de Mar del Plata, Argentina

Fecha de recepción: noviembre 2018. Fecha de aceptación: julio 2019.

\begin{abstract}
Resumen
El artículo resume la mirada del lector hispanoamericano del primer cuarto de siglo XIX construida a partir de las producciones del escritor español José Joaquín de Mora quien se ocupó de editar, traducir y escribir textos pensando en la construcción de ese lector, en tanto aprendiz y par. Tomo a José Joaquín de Mora como autor de la empresa Ackermann durante su primera estancia en Londres, entre los años 1824 y 1826 a partir de dos de sus traducciones y catecismos.
\end{abstract}

\section{The Ocean World. José Joaquín de Mora writes for the Hispanic-} American public (1825-1830)

\begin{abstract}
It summarizes the construction of the Latin American reader in Catechisms and translations that have been made by an exiled spanish writer, José Joaquín de Mora, during his first stay in London (1824-1826). This reader image has been built as an apprentice and a pair at the same time.
\end{abstract}

\section{Resumo}

O artigo resume o olhar do leitor ítalo-americano do primeiro quartel do século XIX, construído a partir das produções do escritor espanhol José Joaquín de Mora, responsável por editar, traduzir e escrever textos pensando na construção desse leitor, como aprendiz e par. Eu estudo José Joaquín de Mora como autor da empresa Ackermann durante sua primeira estadia em Londres, entre 1824 e 1826 a partir de duas de suas traduções e catecismos. ${ }^{1}$

\section{Palabras clave}

José Joaquín de Mora Prensa

Traducciones

Catecismos

Hispanoamérica

\section{Keywords}

José Joaquín de Mora Press

Translations Catechisms LatinAmerica

\section{Palavras chave}

José Joaquín de Mora Imprensa

Traduções Catecismos Hispamerica

1. Agradezco la gentileza del Mgter. Hernán José Morales por la versión portuguesa del resumen. 


\section{Introducción}

José Joaquín de Mora es un actor fundamental del panorama literario-periodístico del siglo XIX español e hispanoamericano. Formó parte de una generación aquejada de nomadismo a raíz de las vicisitudes políticas que atravesaron las vidas de sus integrantes y las de sus lugares de origen. Nacido en Cádiz en 1783, desde muy joven asistió a las transformaciones que los sucesos revolucionarios de principios de siglo XIX impactaron en la vida intelectual del sur de la Península. Para empezar, el movimiento producido en la Corona respecto del traslado de la Casa de Contratación situada en Sevilla desde su fundación en 1503 a Cádiz, en 1717, impuso nuevas perspectivas a su puerto y a su sociabilidad. Casi cien años después, en la juventud de De Mora, Cádiz se convirtió en una ciudad sitiada, acosada por el ejército francés. No dejó de ser, sin embargo, una ciudad activa en su comercio exterior y bien abastecida, con una ciudadanía dispuesta a celebrar una Constitución (1812) y que sería uno de los modelos -y no el de menor impacto- para las constituciones hispanoamericanas y sus urgencias locales (Landavazo y Sánchez, 2014). De Mora vive el desarrollo y debate de la libertad de imprenta y de expresión que se da en las cortes gaditanas y que irradiará de forma significativa tanto en el ámbito de la prensa local y de las instituciones educativas y literarias como en los territorios ultramarinos, muchos de ellos ya con nuevos regímenes. Estos espacios, cercanos a la mitología, a mundos lejanos, serán pensados por De Mora al calor del aire constitucionalista y liberal en el que fue educado, como los imaginaban, también, carbonarios, mazzinianos y liberales. Al mismo tiempo, hombres de negocios y editores vieron en América la apertura cierta de un mercado para la prensa, el libro, objetos de arte, etc. (Durán López, 2015). La conjugación de ambas cuestiones provocó una amalgama que se vio expresada en la prensa periódica y en la producción literaria para América.

Los distintos emprendimientos que se desarrollaron en Londres, primero, y luego en Latinoamérica fueron empresas de articulación de carácter intelectual, mercantil y político entre el mundo europeo y el escenario local que se produjeron en un marco de no pocas dificultades de ejecución y de perspectivas, por una parte, y que, por la otra, construyeron una figura de intelectual, como el caso de De Mora, al calor de ese nomadismo, no sólo físico sino también ideológico - característica del grupo de emigrados españoles del primer cuarto del siglo XIX (Durán López, 2015). Trabajar para el editor Rudolf Ackermann representó para De Mora una fuente económica fundamental de subsistencia diaria y para la realización de proyectos propios como las traducciones y la escritura de textos literarios; ${ }^{2}$ su elaboración buscará el mercado - con el presupuesto de procurar una literatura entretenida, ágil y por momentos educativa- desde la fragmentación y la mezcla discursiva.

La presencia de americanos en París o Londres, como mandatarios, agentes del gobierno, etc., es una variable a considerar. Los americanos buscaron, primero, que los europeos reconocieran la independencia de sus países - por ejemplo, el viaje de Rivadavia y Belgrano a Londres en 1814 y la posterior estancia del primero hasta 1820 o la larga residencia de Andrés Bello en Londres, desde 1810 a 1829-e intentaron, como consecuencia, atraer a los hombres de prensa y de ideas para conformar las futuras repúblicas. Este mundo océano, como lo ha definido el historiador Thomas Bender (2011), constituyó, para un gaditano como De Mora, una renovada forma de convivir con las referencias a una América liberal en la vida diaria. Pocos años después, esas referencias se encarnarán en la figura de Bernardino Rivadavia, quien permanecerá en la memoria de De Mora como epítome de un liberalismo alguna vez soñado e imaginado (Baltar 2014: 140).

Hay muchos estudios que en la actualidad abordan la figura de De Mora a la par que reflexionan en torno a los exiliados liberales que iniciara la investigación señera 
de Vicente Llorens desde su estancia en Princeton en el texto imprescindible todavía Liberales y románticos (1954). Sin embargo, como señala Alejandra Pasino para el caso de José Blanco White, "ese logro historiográfico ha tenido escasa repercusión en nuestro país a pesar de que un importante número de publicaciones estuvo dirigida a los hispanoamericanos" (Pasino, 2014:148). Según Amunátegui, trabajaban en los talleres del editor más de seiscientas personas (33). La empresa se había organizado para surtir de libros a todos los países de Hispanoamérica. El hijo mayor de Ackermann se había establecido en México para distribuir los volúmenes. El editor tenía agentes y puntos de venta en Argentina, Colombia, Chile, Perú y Guatemala. Para mantener la maquinaria de su empresa en funcionamiento le hacía falta una amplísima producción y una generosa oferta de títulos. Los textos que analizaremos aquí han sido escritos para ser leídos por los hispanoamericanos desde Londres o desde la misma América, constituyendo un lector que comparte la mirada liberal (o simplemente, porque es un lector americano, no contaminado de Restauración) al que se le brinda insumos para aprender y poner en ejecución esos ideales en un mundo todavía por hacer ${ }^{3}$ y al que, como se verá, es necesario precaver y librar de impurezas.

\section{Traducir para el lector de las nuevas repúblicas}

En 1825, Walter Scott (1771-1832) publica el segundo tomo de su Tales of Crusaders, The Talisman y, al año siguiente, deMora traduce la novela al castellano con el título El talismán. Cuento del tiempo de las Cruzadas para el editor Rudolf Ackermann, poco afecto a sostener económicamente traducciones de novelas o textos de ficción, pero, quizás, en este caso, llevado por el éxito rutilante que el "célebre anónimo", como le llama De Mora a Scott, tenía por esos días en toda Europa. De Mora había traducido Ivanhoe (primera edición en inglés de 1819), novela que ya contaba con traducciones parciales, breves pasajes adaptados en otra empresa de Ackermann, el periódico Variedades o el Mensagero de Londres a través de la pluma de Blanco White. Se han estudiado las diferencias de criterios de De Mora y de Blanco White a la hora de traducir: la destreza de la lengua inglesa, el compromiso ideológico con un tipo de religiosidad, la puntualidad respecto de las explicaciones geográficas, idiosincráticas e históricas (Rodríguez Espinosa 2007; Durán López 2015: 119-127); sin embargo, a nuestro efecto, es importante la diferencia respecto del interés por el destinatario de la traducción, interés en el que los propósitos del empresario editor y del traductor se aúnan significativamente: pensando en la recepción hispanoamericana conjugan los deseos comerciales de la edición y la creencia -compartida por varios exiliados- de que en América, todavía, podía conformarse de manera efectiva el ideal político liberal frente al enceguecido mundo europeo de la Restauración. Hacia el final del prólogo a la traducción de El talismán, apunta De Mora:

Nos lisonjeamos con la esperanza de que los pueblos de la América que fue española, rectificadas sus ideas en fuerza de las reformas políticas que han abrazado, sepan apreciar, aun en los ramos de lujo y recreo, lo que es realmente bueno, por estar de acuerdo con las reglas eternas del orden. Si merece su aprobación este ensayo, no tardaremos en ofrecerle las obras maestras de la misma pluma (1826: xi). ${ }^{4}$

El deseo de que América, bajo un orden político nuevo, republicano, apreciara una literatura "realmente buena" va de la mano de una discusión de carácter literario y moral: ¿qué es lo realmente bueno, esto es, aquello que está "de acuerdo con las reglas eternas del orden"? Para De Mora, Scott está libre de los vicios de románticos como Chateaubriand o Goethe, cuyos personajes no proporcionan un sano aprendizaje sino la exposición de temperamentos volubles y caprichosos. Es
3. El público hispanoamericano requiere aprender lo que autores como De Mora ya saben o tener lo que en Buenos Aires falta (desde un laboratorio de química hasta plantas y semillas, libros e ideas), como se ve en la correspondencia de Rivadavia o en las páginas de la Crónica política y literaria de Buenos Aires (1827), entre otros escritos de De Mora.

4. Todas las citas de los periódicos conservan la ortografía, puntuación y sintaxis originales. Utilizamos la edición traductológica facsimilar de Marcos Rodríguez Espinosa (2007). 
más: la maestría de la pluma de estos autores hace mayor el peligro de transmisión de emociones y pensamientos reprobables. ¿Qué distinguiría a los personajes de Scott de los protagonistas de las novelas de Goethe o Chateaubriand, a quienes se condena?

En primer lugar, Scott escribía novelas históricas: "aunque los sucesos que forman su nudo son fabulosos, están retratados en ellos con la mayor propiedad los personajes históricos que introduce, y "su lectura puede suplir la falta de los libros de erudición que es necesario consultar para enterarse de ellas". (1826: V). Es decir, fomentan la imaginación al tiempo que "producen una utilidad real", que es hacer familiares las ideas "dominantes", "con los usos, preocupaciones, ceremonias y modales". En segundo lugar, en Scott se cifran las esperanzas de De Mora de que el público se revele frente al espejismo que le produce la "literatura moderna" y sus "insípidas caricaturas" por la afición que sus pinturas generan:

Nuestro autor, lejos de abusar de las grandes prendas que como escritor posee, las emplea en objetos más nobles y, si nos hace amable la virtud, no es presentándonos un simulacro vicioso revestido de su nombre y formado de elementos enteramente contrarios a los suyos, sino pintándonos sus modelos y dándonos a conocer amantes respetuosos, enemigos generosos y magnánimos, amigos fieles, servidores leales y mujeres sensibles, pero recatadas, que no cifran tida su existencia en la pasión, ni se creen nacidas para inspirar y hacer locuras. (1826: X).

Antes de continuar este análisis, detengámonos en las primeras traducciones de deMora, en su primera juventud. Para llegar al día en que inicia la traducción de Scott, de De Mora ya ha atravesado dos exilios, se ha graduado como abogado en Granada y ha dictado clases en la Universidad -Lógica-, ha sido editor y redactor de varios periódicos en Cádiz y Madrid y ha sostenido la conocida "querella calderoniana" sobre el romanticismo, en un diálogo entre periódicos y traducciones mediante. En ese debate, Bölh de Faber escribe un texto, "Sobre el teatro español", publicado en el Mercurio gaditano en el que exalta los valores monárquicos, religiosos y tradicionales a través del teatro calderoniano, los cuales, desde las páginas de la Crónica científica y literaria (Madrid, 1817-1820) son refutados por José Joaquín de Mora y Alcalá Galiano, partidarios de un sistema de gobierno basado en la monarquía constitucional. Más allá de que en ese momento ambos cronistas defendieran las pautas estéticas clásicas, la asociación entre estética, ética y política es central en De Mora y marcará sus decisiones críticas o editoriales. Lo clásico en aquel contexto se presenta como una reserva moral frente a la reacción borbónica y la aceptación del romanticismo por parte de sus defensores (Bohl de Faber). Sin embargo, la mayor parte del periódico procede como un resumen de noticias londinenses, en las que se privilegia información que contravenía el ideal de una España tradicional, católica, localista que tanto el régimen monárquico como los estetas románticos propugnaban. Siempre con el cuidado de subrayar pleitesías al rey, en un marco de censura y autocensura (Baltar, 2018), De Mora favorece la difusión de las ideas liberales, en particular, el precepto de que un gobierno no puede estar librado a los caprichos de un solo hombre como ocurría con el absolutismo en el que, como se cuenta en una memoria sobre el gobierno de Fernando VII, la personalidad del monarca no se encuentra sujeta a ley alguna:

En un país como la Inglaterra, donde el soberano ecsiste bajo el poder de las leyes, es raro que su carácter personal tenga consecuencias políticas de importancia: mas no sucede así en las monarquías absolutas como la española. Las prendas personales del soberano influyen poderosamente sobre todas las ramas del gobierno: todo emana de su única voluntad: y cuanto puede obrar, de cualquier modo que sea, sobre esta voluntad debe ocupar un lugar en la historia política de la nación (1840: IV-V [1824]). ${ }^{5}$ francés, fue publicado en Londres por Michael Quin en 1824. Seguimos la traducción de Joaquín García Giménez de 1840, publicada en Valencia. Edición facsimilar. 
Como contraste con ese mundo regido por leyes no escritas pero que se cumplían, Fernando VII protagoniza una escena de lectura divulgada como chisme de época impactante para los exiliados y que, en un punto, en esa nueva asociación entre estética y política, selló la perspectiva negativa sobre aspectos de ciertos románticos:

Como las relaciones que ecsisten entre la Península y la Santa Sede pertenecen naturalmente á los negocios eclesiásticos, hablaremos con esta ocasion de aquellas: únicamente añadiremos que el partido que en la córte de las Tullerías sostenía los principios que Fernando ponia en práctica, admiraba la conducta del mal aconsejado príncipe, y proponía á toda Europa su gobierno como un modelo digno de imitarse. El vizconde de Chateaubriand publicó en diciembre de 1819 un escrito muy elocuente, en el que procuraba probar la solidez, la belleza, la justicia y los grandes resultados de semejante sistema de gobierno. Hallábase Fernando leyendo este folleto cuando recibió la noticia del pronunciamiento de las Cabezas de San Juan. (1840: 180 [1824])

Fernando VII lee a Chateaubriand, ¿qué hacía Fernando VII "leyendo", "recibiendo una noticia" en medio del desorden general? Una noticia que ponía fin, al menos momentáneamente, al sexenio absolutista que llevaba adelante el monarca y que lo obligaría a jurar, nuevamente, fidelidad a la constitución de 1812. Esta imagen de pasividad y de adhesión a los preceptos absolutistas que implicaba estar leyendo El genio del cristianismo es penetrante y, a diferencia de, por ejemplo, Fray Servando Teresa de Mier y Simón Rodríguez, traductores de Atala(1801), no es posible para De Mora sino sancionar negativamente este u otro texto del escritor francés:

Las novelas que mas nombradia han adquirido en estos ultimos tiempos [Atala, Corinne, Julia o la Nueva Heloisa, Werther] estan impregnadas de los vicios que necesariamente han adquirido los pueblos, al llegar a cierto grado de civilizacion; el egoismo reconcentrado, que sacrifica las consideraciones mas sagradas a la satisfaccion de una pasion dominante; la refinada hipocresía, que cubre con el manto de la virtud, los mas criminales exesos; la exasperacion del orgullo, y el delirio de la soberbia, que terminan por una muerte voluntaria las desventuras ocasionadas por los mas torpes extravios. (1826: ix -x)

En novelas como Atala, De Mora ve prácticamente la personalidad y las aptitudes de la monarquía restauradora como en un espejo. Y la justificación tal vez fuera sostener que mientras en El Talismán o Ivanhoe dominan los elementos de la novela histórica $\mathrm{y}$, por tanto, son relatos que suplen la historia cuando no tenemos ese tipo de libros, que más allá de la trama existe un fundamento útil, en Atala y textos semejantes sobrevuela, por encima de todo, la irracionalidad y la pasión personal:

Al leer semejante conjunto de desacuerdos no parece sino que el hombre ha sido colocado en la sociedad para abandonarse sin freno a sus apetitos, para encaminarse al logro que se propone por los medios más prontos y fáciles y para retirarse por sí mismo de la escena cuando las circunstancias se han opuesto al cumplimiento de sus miras. ¿Qué otra moral es la que enseñan Werther, Saint Preux, Oswald y otros personajes que, por desgracia, han dado en manos de ingenios de primer orden que han sabido seducir en copa de oro y dar a la insensatez y al delito un idioma encantador e irresistible? (1826: X)

Con respecto a Chateaubriand hay un detalle que no debemos olvidar: De Mora lo había traducido en 1814. En el prólogo a De Bonaparte y los Borbones, el autor francés es elevado por De Mora a la categoría de genio. El texto es un alegato decidido en contra de la avanzada napoleónica y coincide con la posición política en ese momento del traductor. Posteriormente, en un comentario crítico a una publicación musical, De Mora describe la pintura "El entierro de Atala" de Girodet-Trioson (que atribuye 
erróneamente a Gerard, otro discípulo de David) donde anota la reflexión de que la historia "elocuente" de Chateaubriand es la "historia de la debilidad humana, sometida al imperio de la religión" (Crónica científica y literaria 25/04/1817, p. 3, col 2), y aquí De Mora lee, otra vez, la historia de Chateaubriand, valorando su estética y la visión de las cosas que propone. Pero, diez años después, cuando Chateaubriand pinte una España exótica y tradicional, cuando defienda la Restauración y erija el cristianismo en el paradigma rector de la vida, incluso política, De Mora se distancia de la mirada admirativa de antes y condena las características de las novelas del autor francés por perniciosas. Los vaivenes políticos determinaron en De Mora sus apreciaciones como crítico lector.

Pareciera, entonces, que Scott no sólo propone personajes no viciados sino modélicos y que los otros escritores traman personajes dominados por sus pasiones individuales y egoístas. Ahora bien, cuando aparecen marcas de subjetividad en el texto de Scott, la traducción de De Mora (nos referimos a El Talismán) muestra ciertas operaciones que buscan atenuarla. En su estudio traductológico -y al que remitimos- Marcos Rodríguez Espinoza indica, por ejemplo, que los epígrafes presentes en el original al inicio de cada capítulo han sido omitidos (recuperados luego por una traducción posterior en más de un siglo, en 1971) y que las notas de Scott han sido sometidas a diversas intervenciones (omisiones, reescrituras, sustituciones por otras del traductor): la naturaleza de esta intervención conduce a reafirmar una lectura que ancle en la historia y no tanto, como dice De Mora, en la fábula, a través de la información geográfica y jurídica que el traductor inserta. Los epígrafes omitidos en su totalidad (de procedencia anónima, baladas tradicionales, viejas y populares obras de teatro en su mayoría) dejan advertir la fuerte filiación de Scott con la sensibilidad romántica, lo que acentuaría su aspecto fabuloso, ficcional. De Mora apunta a consolidar una lectura de la novela como complemento del acontecer histórico. Pero, fundamentalmente, las intervenciones de De Mora tienden a pensar en el interés del público hispanoamericano, al que debía acercarle información precisa de ciertos datos geográficos o de sistema de gobierno y al que se piensa como nuevo y no viciado.

En el prólogo a su primera traducción de Ivanhoe, De Mora discute los beneficios del género novela. Se trata de un prólogo, a la manera de Cervantes, esto es, un "Diálogo en vez de prólogo" entre el traductor y un amigo imaginario. Las metáforas de cómo prende la literatura, para bien o para mal en el público remiten a epidemias, a enfermedad contagiosa.

¿Qué es una novela? ¿Es más que un tegido de patrañas, de embustes, de tramoyas, en que ni se ve la sombra de un silogismo (...)? (...) ¡Novelas! Hartas inmundicias tiene ya la pobre literatura castellana sin esta nueva peste, capaz de inficionarla misma biblioteca de Alejandria. Ya que con dos mil santos tiene V. esa renegada comezon de escribir que hoi aqueja a todo el genero humano...". (IV El subrayado es mío).

El pasaje muestra con claridad cómo De Mora se apropia de la concepción sobre lectura y lectores que, operando desde la multiplicidad y cantidad, provocaron lo que Chartier llamará "revolución de la lectura" y que describe en los términos percibidos como agitación mental en consonancia con el cuerpo lector en reposo (Chartier 2006: 195). Sin embargo, claramente se trata de la apropiación de la palabra ajena en términos paródicos por medio de la cual el narrador, en verdad, proporciona como contrargumento de su propia actividad, la de traducir una novela. El amigo recomienda al traductor que, "ya que quiere V. emplear sus talentos en obsequio de los Americanos, ¿porque no escribe V. algun buen compendio de las Sumulas de Villapando o algun comentario profundo a Sanchez de Matrimonio? Así, libros de carrera... de pane lucrando. (IV. Cursivas en el original)" 
El debate se mueve en dos sentidos: por un lado, entre una nueva literatura y la educación tradicional, de cuño escolástico, que irritaría a un exiliado liberal, abogado, tanto como se daba ese debate en el ámbito hispanoamericano (podemos ver este tema en Recuerdos de Provincia o en Mi vida privada o en Diego Alcorta y sus lecciones de filosofía). La traducción de la novela es aquí funcional a un deseo de dejar atrás las formas de enseñanza del mundo católico en el antiguo régimen y a las ansias de los americanos por esos libros traducidos, extranjeros, para vindicar lo nuevo y desprenderse del lastre colonial. Es decir, se trata de una discusión entre el pasado y el presente. Por otro lado, para De Mora es un planteo que tensa la arena política actual porque la escolástica es sinónimo de presente, de mundo restaurado, de Fernando VII restituyendo los poderes de la Inquisición que habían sido suprimidos durante el trienio liberal.

Pero, y en esto hay una distancia con los americanos, De Mora discierne dentro del género novelístico unas narraciones, como las de Scott, "saludables" y otras, contagiosas de males morales, sociales y personales. No hay que olvidar la doble situación de la literatura en la península: de una parte, los escritores locales, prohibidos, exiliados o prisioneros en su patria; de la otra, la propia península siendo objeto de consideración en libros como los de Chateaubriand que rescatan el color local, el exotismo a través de la literatura de viaje y que contrasta con la experiencia misma de De Mora que ve en todo eso la confirmación de una monarquía endeble y reaccionaria.

De Mora procura, entonces, transmitir mensajes purificados, no viciados, filtrados por esta mirada tutelar que tendrá mucha fuerza en la generación romántica rioplatense cuando esté pensando en el pueblo, en su instrucción. Gracias a Ivanhoe, la fama de Scott "ha cundido por toda Europa", pero también los "vicios", el "egoísmo", "la refinada hipocresía", "el orgullo", "la soberbia", el abandono sin frenos a los apetitos particulares a través de otras novelas. La enumeración rítmicamente acelerada de estos defectos que publicitan tramas como las del joven Werther, Saint -Preux u Oswald acentúan la necesidad de un nuevo Quijote para los tiempos de corrupción que corren, al punto de que la empresa de Cervantes resulte en la actualidad una nadería: "Y, sin embargo, ¿qué diferencia entre las inocentes lecturas de los paladines y la refinada corrupción de la mayor parte de los héroes y heroínas que figuran en las novelas de nuestro siglo?" (1826: viii) De Mora se arroga una misión ante el lector hispanoamericano: ofrecerle aquello saludable, útil, y no lo que podría inocular toda una suerte de catástrofes.

\title{
Redactores y lectores de catecismos
}

\author{
$P: ¿ D e$ qué se compone el globo? \\ $R$ : De cielo y tierra \\ Catecismo de geografía universal para la instrucción
}

La publicación de los catecismos propone un escritor en Londres y un lector en América: entre ambos, el inmenso océano y, sin embargo, la comunicación a través de concepciones en común expresadas en ese objeto pequeño, compendio de saberes, que es el catecismo. De Mora los redacta para la empresa Ackermann y Sarmiento, en su San Juan natal, los lee:

En 1826 entraba tímido dependiente de comercio en una tienda, yo que había sido educado por el presbítero Oro en la soledad que tanto desenvuelve la imaginación, soñando congresos, guerra, gloria, libertad, la república en fin. Estuve triste muchos días, y como Franklin, a quien sus padres dedicaban a jabonero, él que debía robar al cielo los rayos y a los tiranos el cetro, toméle desde luego ojeriza 
al camino que sólo conduce a la fortuna. En mis cavilaciones en las horas de ocio, me volvía a aquellas campañas de San Luis en que vagaba por los bosques con mi Nebrija en las manos, estudiando mascula sunt maribus, e interrumpiendo el recitado para tirarle una pedrada a un pájaro. Echaba de menos aquella voz sonora que había dos años enteros sonado en mis oídos, plácida, amiga, removiendo mi corazón, educando mis sentimientos, elevando mi espíritu. Las reminiscencias de aquella lluvia oral que caía todos los días sobre mi alma, se me presentaban como láminas de un libro cuyo significado comprendemos por la actitud de las figuras. Pueblos, historia, geografía, religión, moral, política, todo ello estaba ya anotado como en un índice; faltábame empero el libro que lo detallaba, y yo estaba solo en el mundo, en medio de fardos de tocuyo y piezas de quimones, menudeando a los que se acercaban a comprarlos, vara a vara. Pero debe haber libros, me decía yo, que traten especialmente de estas cosas, que las enseñen a los niños; y entendiendo bien lo que se lee, puede uno aprenderlas sin necesidad de maestros; y yo me lancé en seguida en busca de esos libros, y en aquella remota provincia, en aquella hora de tomada mi resolución, encontré lo que buscaba, tal como lo había concebido, preparado por patriotas que querían bien a la América, y que desde Londres habían presentado esta necesidad de la América del Sur, de educarse, respondiendo a mis clamores enviándome los catecismos de Ackermann, que había introducido en San Juan don Tomás Rojo. ¡Los he hallado!, podía exclamar como Arquímedes, porque yo los había previsto, inventado, buscado aquellos catecismos, que más tarde, en 1829, regalé a don Saturnino Laspiur para la educación de sus hijos. Allí estaba la historia antigua, y aquella Persia, y aquel Egipto, y aquellas Pirámides, y aquel Nilo de que me hablaba el clérigo Oro. La historia de Grecia la estudié de memoria, y la de Roma en seguida sintiéndome sucesivamente Leónidas y Bruto, Arístides y Camilo, Harmodío y Epaminondas; y esto mientras vendía yerba y azúcar, y ponía mala cara a los que me venían a sacar de aquel mundo que yo había descubierto para vivir en él. Por las mañanas, después de barrida la tienda, yo estaba leyendo, y una señora Laora pasaba para la iglesia y volvía de ella, y sus ojos tropezaban siempre día a día, mes a mes, con este niño inmóvil, insensible a toda perturbación, sus ojos fijos sobre un libro, por lo que, meneando la cabeza, decía en su casa: “Este mocito no debe ser bueno! ¡Si fueran buenos los libros no los leería con tanto ahínco!". (Sarmiento: 210-212. Cursivas propias.)

La escena de lectura, tantas veces estudiada, pertenece a Recuerdos de provincia. Como suele suceder, una página de Sarmiento condensa atmósfera, contexto, datos y emociones con una gran síntesis de sentidos. Sarmiento representa una vez más la escena de lectura en la cual él inventa el libro, crea el libro con la fuerza de su deseo, un librito que llegará después: "el libro no es meta sino prefiguración", nos dice Sylvia Molloy, quien agrega "disonante conjunto de textos a menudo fragmentados, de trozos sueltos de escritura, es materia para comienzos" (26). En esta ocasión, son los catecismos que "suena[n] en el oído" del lector, editados por Ackermann en Londres y que responden a los clamores de este joven dependiente, quien convierte a los anónimos autores, con la lectura, en patriotas que pensaban en el libro para la educación de América independiente. Como la fiebre, el cuerpo en la inacción, inmóvil, y la cabeza bullendo, incansable; la voz anterior, la lluvia oral, ahora es un catecismo impreso, que habla desde la visión.

Ackermann lo tenía todo estudiado. Desde el siglo XVIII esta lectura era aceptada en América y su experiencia empresarial le hacía, muchas veces, copiar formas ya probadas - como había hecho, en paralelo con los Forget me not traídos a Londres desde Alemania y traducidos y adaptados, a su vez, para el público hispanoamericano-. Siguiendo el formato de preguntas y respuestas del catecismo religioso, se trata de un tipo textual muy difundido, que había circulado como lectura política para la difusión de las ideas de los filósofos franceses del siglo XVIII. En 1788 se había impreso en 
Madrid, precisamente, un Catecismo de los filósofos o sistemas de la felicidad, un pequeño librito de regalo, devoto, en cuyo corazón ilustrado estaban escritas las ideas antimonárquicas que no hubieran sido del agrado de los censores, quienes, por otra parte, hicieron circular catecismos monárquicos en toda América, sumados a la cuantiosa actividad propagandística que se daba a través de los sermones. En la América del Sud, por ejemplo, se publicó en Chile el Catecismo Político y Cristiano (1810) en el que se "advierte la cultura clásica del autor, el conocimiento de textos legales y la fuerte hostilidad frente a las autoridades" (Donoso 12) y un año más tarde, en Buenos Aires, la Imprenta de Niños Expósitos imprimió el Catecismo público para la instrucción de los neófitos o recién convertidos al gremio de la sociedad patriótica que atravesó las fronteras andinas y fue objeto de debate y réplica en cada púlpito y salón. En 1813, en las páginas de El Monitor Araucano se publicará un Catecismo de los patriotas, abogando por la libertad de imprenta y la necesidad de formular una constitución, intereses comunes a lo que se estaba dando en las Cortes de Cádiz:

¿Cuál es una de las señales más claras de la libertad pública?

La libertad de imprenta

qué bienes resultan de la libertad de imprenta

el denunciar al público todos los abusos

el propagar las buenas ideas el intimidar a los malos

el de proponer sabios reglamentos y útiles reformas

el combatir los sistemas perjudiciales

en fin, el extender los conocimientos humanos. (Citado en Donoso V)

Otro curioso papel, el Catecismo o dispertador patriótico cristiano, de 1813, aparece dedicado a "Paisanos y Militares voluntarios de las provincias de Salta, que se llaman Gauchos" y su autor cubre todo un espectro de posibles lectores: en los paratextos, hay una referencia general ( "Ilustres generosos chilenos", "Habitantes todos de Chile", "Compatriotas amados", "Carísimos compatriotas"), pero luego, en un estilo que nos recuerda el texto ya clásico de Eliseo Verón, su previsto "Lector mío" se divide en "realista español", "patriota americano" y "egoísta, neutral y mirón". Tanto el "realista" como el "patriota" son tratados con respeto y se procura hacerlos razonar con argumentos mientras que al "egoísta" se lo descalifica e injuria.

Es decir, estos "catecismos" eran herramientas políticas y facciosas que, usadas desde hacía tiempo para distintos fines, mantienen en la empresa Ackermann el perfil divulgativo y el formato, pero cambiaron en cuanto al tono político y postularon una escritura fragmentada, aforística, para instruir y satisfacer las necesidades que se suponía tenía el público hispanoamericano como las palabras de Sarmiento evidencian. Vicente Llorens describe: "Los Catecismos [de Ackermann]eran atractivos y manejables; pequeños volúmenes en $12^{\circ}$, de unas ciento a ciento cincuenta páginas, impecablemente impresos, con láminas y grabados como no se hacían entonces más que en Inglaterra. Su precio, dos chelines" (1954: 172).

En la prensa de la época, estos catecismos fueron promocionados a partir de justamente sus aspectos decorativos, en el sentido de objetos -como también lo eran los No me olvides: "bien bruñidos e ingeniosamente confeccionados" (T IV, 1825, 21/12, 505, Ocios). En las manos de un ávido dependiente de provincias un catecismo de la empresa Ackermann provee de sueños y conocimiento en ese paisaje desértico de obras. El punto de vista de aquellos lejanos redactores.De Mora, Mendeville, entre otros, que imaginaban una América idealizada, tuvo en común con el joven que luego sería Sarmiento, un concepto de nuevo lector. Increíblemente, en las manos de Sarmiento se hallan los textos de José Joaquín de Mora, quien, al tiempo que los redacta, los promociona en otros periódicos destinados al público de América, por ejemplo, en el Museo universal de ciencias y artes: 
Así pues el consejo más provechoso que puede darse a los gobiernos de América, que por una feliz reunión de circunstancias se hallan exentos de los males que aquejan a la mayor parte de los pueblos antiguos, es que promuevan por todos los medios imaginables la educación de la juventud. No puede haber ciudadanos donde no hay elevación de sentimientos y solidez de principios, y estos resultados no se adquieren sino por medio de la educación. Para llevar adelante tan grande obra no se debe aspirar de pronto a una perfección que solo puede ser hija del tiempo; adóptense todos los medios que generalizan y difunden los conocimientos útiles y en breve se vera cuanto se extienden y fecundan estas semillas. Los libros elementales, breves, baratos, escritos con sencillez y con gusto contribuyen singularmente a un fin tan útil. (Citado en Candel 155)

La difusión aparece en la Revue encyclopédique, ou Analyse raisonnée des productions les plus remarquables dans les sciences, les arts industriels, la littérature, et les arts

\section{EUROPE}

\section{GRAND BRETAGNE}

4-Catecismos, de ciencias y artes, etc. Cathechismes

Catecismos de ciencias y artes, etc. Catecismos de las ciencias y de las artes. Las entregas que han sido publicadas comprenden: los catecismos de química, de geografía, de agricultura, de astronomía, de aritmética, de geometría, de economía rural, economía política, de moral, etc. Londres, 1825 1826, R. Ackermann. Cada catecismo forma un volumen en 13, de 120 páginas a dos chelines. Esta colección de libros elementales, publicados en castellano, y destinados a la educaicón pública de las jovenes nuevas reúblicas ha merecido la aprobación del ilustre Lancaster, la del gobierno de Colombia, quien los ha distribuido en todas las escuelas. Los redactores de estas pequeñas obras que estan impresas con mucho cuidado y buen gusto han tenido el buen espíritu de adaptar las obras de un mérito indiscutible para abreviarlos y ponerlos al alcance de la juventud americana. Siguieron para química la gran obra de Parkes; para economía política los tratados de Mill y de Ricardo y así con el resto. Destacamos especialmente el catecismo de moral escrito por el español Villanueva, este pequeño libro ya es popular en todas las repúblicas de América del Sud. JJM (Mi traducción. Volumen 31 1826: 114)

El catecismo de economía política es una cantera de nuevas producciones periódicas para José Joaquín De Mora. Todavía, en el diario de 1854, La América, crónica hispanoamericana (Madrid, 1857-1886) en la que escribe él y también Juan Bautista Alberdi, se reproducen esos artículos de enseñanza y resumen de los tratados de Mill que habían sido publicados, a su vez, en otras empresas americanas de De Mora, entre ellos en el Mercurio chileno (1827).

El instinto publicitario de la dupla De Mora-Ackermann recorre otras páginas, las del Correo político y literario de Londres, escrito y editado por ellos mismos.

No faltará quien diga que la obra de la que estamos hablando pertenece al número inmenso de las que se hacen a pedazos y aprovechándose del fruto de los trabajos ajenos [...] Sin embargo la historia no es susceptible de las creaciones de la fantasía y todo el que quiera saber lo que ha pasado de las épocas que le han precedido se hallará obligado a buscar en las obras de su coetáneos. La dificultad es escoger, es arreglar, es lograr el simplex et unum que Horacio recomienda. El autor de los Cuadros ha procurado desempeñar aquel fin, pero el redactor del Correo no puede decir si en efecto lo ha logrado. (Citado en Rodríguez Gutiérrez 132)

Fragmentos: he aquí a José Joaquín de Mora, trabajando casi exclusivamente a través del fragmento y de otras estrategias que, en todos los casos, indican torsiones, 
intervenciones sobre un texto precedente, procedimientos por otra parte habituales en los escritores de la época. Los catecismos, fundamentalmente, exhiben una concepción de la educación como la manera excluyente de modificación de las costumbres, como herramienta para la civilización y como elemento clave para la implantación de un mundo liberal decisivo que debió ser importante para Sarmiento. Como vimos, en el prólogo a la traducción de Scott que comentábamos al inicio, De Mora pensaba en la literatura como un elemento supletorio, que podía reemplazar, cuando estaba de acuerdo con el orden de las cosas, a la historia; del mismo modo, los catecismos son pensados como un "comienzo" y también como un modo de aproximación a cierta bibliografía o a un libro entero. A diferencia del periódico, que para Sarmiento será insustituible, los catecismos, las revistas como los No me olvides, e incluso las novelas, son textos subsidiarios de otros textos y, más allá de sus propias y en algunos casos novedosas constituciones, constituyen vías hacia otras lecturas.

Hay, sin embargo, mucho más en esta empresa que mero resumen, adaptación y traducción literal, en especial si hablamos de los textos de economía política y de los de gramática; De Mora allí introduce explicaciones que subrayan la tendencia creciente de la economía política (Llorens 172) o inserta de su propia cosecha modificaciones que abren las puertas de la gramática a nuevas orientaciones y renovación. De nuevo, en sintonía con ese lejano lector, escribe en este catecismo:

Las lenguas se han perfeccionado a medida que se han propagado las luces, recibiendo de todas las ramificaciones en que se dividen todos los conocimientos humanos, auxilios poderosos que les han servido para suavizar su primitiva aspereza, para aumentar el caudal de sus voces, para despojarse de toda confusión y oscuridad. (volumen 3, 505, Ocios)

La empresa era lo suficientemente importante como para que diera lugar a una recepción tan extraordinaria como lo revela la referencia sarmientina y fuera de la mano de los propios escribas replicando su interés en otros medios.Existió una reflexión crítica en la prensa, que revela su éxito a la par de la curiosidad que suscitó y las disidencias que provocó entre los mismos emigrados que siendo todos liberales no coincidían en cuanto a la calificación de la lengua ni de la literatura:

Salieron en aquellos mismos días en que andaba yo en estas demandas i respuestas dos gramaticas, la una en castellano por un español i la otra por un inglés para los ingleses; la primera con el título de Catecismo de Gramática Castellana por José Joaquín de Mora, quien por lo mucho que escribe i a la lijera pudiera llamarse pintor de brocha gorda, i otro luca fa- presto que de una chafarrinada se lleva medio lienzo de pared. En el Prólogo después que ha hablado con desprecio de la Gramática de la Academia, cuando el que lee se tiene tragado que es aquella una de nuevo cuño, se halla con que el autor mismo le hace saber que es en sustancia un extracto de la otra; pero atrapó las tantas guineas del librero, i a Méjico con el librejo, adonde fueron también otros libritos bonitos como dijecitos. El tal catequista llevó en los Ocios una buena repasata por su Catecismo, siendo que antes se le aduló a banderas desplegadas, la razón de lo cual parece ser que el librero antes daba también a otros en que ganar, i no dió después. 469. (Opúsculos grammaticos satíricos contra el dr. $d$. Joaquín Villanueva escritos en defensa propia, en los que también se tratan materias de interés común, Antonio Puigbanch Londres, Cuthrie, 1828)

Como vemos, los catecismos eran leídos en todo el mundo hispanoparlante, incluida la península que se hacía eco de los comentarios de De Mora sobre la lengua a través de la crítica. En todos los casos, tanto catecismos, como periódicos y traducciones no se centran en la idea de producción original sino más bien de divulgación, poniendo sobre la mesa una sensibilidad de época tendiente a la formación del público lector 
en las artes prácticas y útiles o, en todo caso, en aquellas de "lujo y recreo", como dice De Mora, pero que acogían formas de la instrucción en historia, economía y hasta legislación. En el público lector hispanoamericano se cifran las experiencias de transformación, de cambio, de novedad, un público abstracto. Sin embargo, pensemos en la experiencia previa al exilio de De Mora, cuando imaginó un público, el peninsular, en medio de la dominación de Fernando VII. Cuando escribió la Crónica científica y literaria se convirtió en el único editor que transmitía una idea de cultura en ese ambiente opresivo, en el que se habían cerrado periódicos, prohibido obras de teatro, impedido la formalización de sociedades al uso de la época como las de economía, agricultura, sociedades benéficas y de ciencias, hasta culminar con el cierre de las universidades en la década ominosa (Asuejo 648); por contraste, ya en 1824, De Mora escribe -este es otro apasionante capítulo, que dejo para otra oportunidadun librito para la instrucción del "bello sexo" en el que presta su voz a "una señora americana" destinado a ser leído por la "Sociedad de Beneficiencia de Buenos Aires" y, a continuación, todas sus colaboraciones en la empresa Ackermann, para terminar escribiendo, en sus primeros días de Buenos Aires, una Crónica política y literaria-es decir, pensando en la alianza entre estética y política que sólo era posible con un público que él, no con total acierto, imaginó liberal.

Me pregunto si Sarmiento se enteró de que De Mora estuvo detrás de esa lectura que lo apasionó, esa lectura que cristalizó en papel sus ansias de libro, de escritura llegada a partir de las voces... Quizás podamos descubrir una expresa conexión; mientras tanto, nos quedamos con un hilo conductor invisible, pero real y apasionante, en el mundo océano que afianzó las iniciativas, logros y catástrofes políticas del temprano siglo XIX, de un mar a otro. 


\section{Q Bibliografía}

》 Bibliographie universelle (1826). Biblioteca Nacional de Francia. Recuperado de Gallica. <https://gallica.bnf.fr/ark:/12148/bpt6k51674f/f69o.image>.

》Crónica científica y literaria (1817-1819). Repositorio de la Biblioteca Nacional de España. Recuperado de <http://hemerotecadigital.bne.es/index.vm>.

»De Mora, J. J. (1826). Gramática Latina dispuesta en forma de catecismo; adaptada al método de enseñanza mutua, sacada de las mejores publicadas hasta ahora en Europa. Londres: Ackermann.

»El Constitucional o sea Crónica científica, literaria y política (1819-1820). Consultado el repositorio de Biblioteca Nacional de España, <http://hemerotecadigital. bne.es/index.vm>.

» García Jiménez, J. (1840). Memorias históricas sobre Fernando Séptimo, rey de España, publicadas en inglés y en francés por Michael J. Quinn. Valencia: Imprenta de Gimeno. Texto digitalizado Google Books.

»Ocios de españoles emigrados, periódico mensual. Segunda Época (1827). Edición facsimilar Biblioteca digital Cervantes, Recuperado de <http://www.cervantesvirtual.com/portales/ocios_de_espanoles_emigrados/>.

»Revue encyclopédique: ou Analyse raisonnée des productions les plus remarquables... Biblioteca Nacional de Francia, 1826, volumen 31. Recuperado de <https://gallica.bnf.fr/ark:/12148/bpt6k105942g/f617.image>.

» Sarmiento, D. F. (1998). Recuerdos de provincia. Buenos Aires: Emecé.

»Scott, W. (1826). El Talimán: Cuento del tiempo de las cruzadas. Traducción de José Joaquín de Mora. Londres, Rudolph Ackermann. Estudio y Edición Traductológica Digital de Marcos Rodríguez Espinosa. Universidad de Málaga, 2007

»Scott, W. (2007 [1825]). Ivanhoe. Traducción de José Joaquín de Mora. Londres: Rudolph Ackermann. Estudio y Edición Traductológica Digital de Marcos Rodríguez Espinosa. Universidad de Málaga. 
